\title{
On Experimental Philosophy and the History of Philosophy: A Reply to Sorell ${ }^{1}$
}

\author{
Justin Sytsma \\ Victoria University of Wellington, Wellington, NZ \\ Jonathan Livengood \\ University of Illinois at Urbana-Champaign
}

\begin{abstract}
In this paper, we reply to Tom Sorell's criticism of our engagement with the history of philosophy in our book, The Theory and Practice of Experimental Philosophy. We explain why our uses of the history of philosophy are not undermined by Sorell's criticism and why our position is not threatened by the dilemma Sorell advances. We argue that Sorell has mischaracterized the dialectical context of our discussion of the history of philosophy and that he has mistakenly treated our use of the history of philosophy as univocal, when in fact we called on the history of philosophy in several different ways in our text.
\end{abstract}

Keywords: Experimental Philosophy, History of Philosophy, Tom Sorell

Tom Sorell opens his paper, "Experimental philosophy and the history of philosophy," with the question: Is experimental philosophy a kind of philosophy? He maintains that it is "at least arguable that, despite calling itself 'philosophy', experimental philosophy is better classified as psychology or some other social science" (1). Sorell then attributes to some experimental philosophers the following response to the criticism that experimental philosophy is really psychology:

[Experimental philosophers] claim that certain historical figures who no-one would deny are philosophers pursued empirical enquiry, and that experimental philosophy stands in the same tradition. ... If contemporary academic philosophy is in tension with experimental philosophy that is because contemporary academic philosophy has lost

\footnotetext{
${ }^{1}$ To appear in the British Journal for the History of Philosophy. Thanks to Tom Sorell for sharing a pre-print of his essay and provoking us to think carefully again about our engagement with the history of philosophy. And thanks to Josh Knobe and an anonymous referee for helpful comments on earlier drafts.
} 
touch with its roots, not because experimental philosophy is actually psychology or some other social science in disguise. (1-2)

Sorell identifies our text The Theory and Practice of Experimental Philosophy (Sytsma and Livengood, 2016) as one of three sources for this response. But as we will argue, the historical response that Sorell attributes to us is not and never has been ours.

Sorell assumes that our discussion of the historical tradition is a response to a criticism and therefore that our discussion aims to justify the claim that experimental philosophy is really philosophy. However, he is not very clear about how the criticism is supposed to go. We think Sorell is imagining an argument something like this:

[A1] If experimental philosophy uses the methods of psychology, then it is psychology (and not philosophy).

[A2] Experimental philosophy uses the methods of psychology.

[A3] Experimental philosophy is psychology (and not philosophy).

Our best guess is that according to Sorell, when experimentalists appeal to the history of philosophy, they are responding to something like this argument. As we draw out later, our discussion of the history of philosophy is not (and never was) intended to respond to an argument that experimental philosophy is psychology. Had we been calling on the history of philosophy in order to respond to the objection that experimental philosophy is psychology, we would have laid out the objection and our response in Chapter 4 of our book, where we respond to purported criticisms of experimental philosophy. Moreover, we would probably not have appealed to the history of philosophy in our reply.

Our first response would likely have been that the argument should be rejected because [A1] is false. To see that [A1] is false, consider the following parallel propositions: 
[A1-a] If logic uses the methods of mathematics, then it is mathematics (and not philosophy).

[A1-b] If formal epistemology uses the methods of statistics, then it is statistics (and not philosophy).

[A1-c] If philosophy of language uses the methods of linguistics, then it is linguistics (and not philosophy).

[A1-d] If interpretive philosophy uses the methods of literary criticism, then it is literary criticism (and not philosophy).

[A1-e] If ethics uses the methods of economics, then it is economics (and not philosophy).

[A1-f] If the history of philosophy uses the methods of history, then it is history (and not philosophy).

All of these propositions (and the general principle from which they flow) are false. One might try to rescue [A1] by adding a qualifier. For example, one might say that if experimental philosophy uses only the methods of psychology, then it is psychology. But then the revised version of [A2] needed to secure the target conclusion would be false. We are not sure that there are any distinctively philosophical methods, but insofar as there are some, which might include developing and reflecting on hypothetical cases, attacking and defending explicitly-articulated arguments, analyzing concepts, and raising skeptical challenges, it should be clear that experimental philosophy makes extensive use of those methods, as we both illustrate and stress in our book (e.g. in Chapter 3, Section 6.1, where we write that "the use of empirical methods should be thought of as a way of supporting the philosophical arguments that you give, not as a way to avoid giving philosophical arguments"). We could go on exploring alternative formulations of the critical argument and showing why they fail. But suffice to say that we see no need to appeal to the history of philosophy in order to resist arguments that experimental philosophy is psychology and not philosophy. 
As Sorell conceives the dialectic, experimental philosophers are responding to the accusation that experimental philosophy is psychology (and not philosophy). How exactly Sorell is imagining the experimentalists' reply is again somewhat unclear, but here is a way it might go:

[E1] Experimental philosophy uses the methods of philosophy.

[E2] If [E1], then experimental philosophy is philosophy.

[E3] Experimental philosophy is philosophy.

The history of philosophy is then brought in to support [E1] in something like the following way:

[H1] If experimental methods were used by canonical philosophers, then experimental methods are among the methods of philosophy.

[H2] Experimental methods were used by canonical philosophers.

[H3] Experimental methods are among the methods of philosophy.

[H4] If [H3], then experimental philosophy uses the methods of philosophy.

[E1] Experimental philosophy uses the methods of philosophy.

Sorell thinks the historical response faces a dilemma: if experimental philosophy is to maintain its "distinctiveness" then it must stress its methods, but its methods are discontinuous with those employed by historical figures. We take it that the dilemma has to do with how to understand premise [H4]. Sorell seems to think that in order to be plausible, [H4] should say, "Experimental philosophy uses the methods of philosophy if the experimental methods distinctive of experimental philosophy are among the methods of philosophy." But amending [H4] in that way would make a suitably revised version of [H2] implausible, since the experimental methods distinctive of experimental philosophy were not used by canonical philosophers. 
We agree that canonical philosophers did not use the methods that Sorell takes to be distinctive of experimental philosophy, namely "the application by philosophers of survey methods, including the construction of questionnaires, the identification and recruitment of research subjects, and the processing of results under constraints of achieving statistical significance" (10). ${ }^{2}$ However, we think that focusing on questions rather than methods is a better strategy for demarcating philosophy. Experimental philosophy is philosophy in virtue of its practitioners asking and attempting to answer philosophical questions. What unites experimental and non-experimental philosophers is the shared targets of their investigations, just as what unites biologists (despite a wide diversity of methods employed) is that they are investigating questions concerning life and living organisms. To assume otherwise is implausible, for if disciplines are demarcated according to their methods, then methodological advances within a single discipline are impossible. So-called "biologists" who use methods of DNA sequencing, for example, would not actually be biologists, since DNA sequencing methods were not employed by biologists prior to the 1970s. Alternatively, if we count researchers using DNA sequencing methods as biologists, then criminal pathologists who use DNA sequencing methods to identify or rule out suspects would be biologists. Using questions instead gets both cases right: people working with DNA sequencing methods to answer questions about life and living organisms as such are biologists, and people using those same methods to answer questions about criminal behavior are not.

In line with our focus on questions, the first section of Chapter 2 of our book ("Philosophical Inquiry") explores some different ways of delineating the targets of

\footnotetext{
${ }^{2}$ We reject Sorell's description of the methods distinctive of the new experimental philosophy. Experimental philosophers have used behavioral experiments, fMRI and reaction time studies, tools of corpus linguistics, and structured interviews, among other techniques. Furthermore, not all research in the new experimental philosophy is concerned with achieving statistical significance: some is non-inferential and some is Bayesian.
} 
philosophical investigations, asking what might make a question philosophical. For each way of characterizing what makes a question philosophical, we indicate how empirical work might be useful. We hold that philosophers are people pursuing philosophical projects and that many such projects can be advanced by doing empirical work. Those people who conduct empirical work in pursuing philosophical projects are experimentalists with respect to method and philosophers with respect to their projects.

In what follows, we further articulate and respond to Sorell's alleged dilemma. We then return to the history of philosophy.

\section{No Dilemma}

In Section II of his paper, Sorell distinguishes between empirically informed philosophy and experimental philosophy. He offers examples of empirically informed philosophy and then states that "these are already familiar specimens of mainstream philosophy, not philosophy requiring a manifesto" (10). He continues:

non-experimental but still empirically informed philosophy... has some of the same motivation as experimental philosophy without making any strong claim to be a methodologically distinctive kind of philosophy.... But the status of the finished result as philosophy seems never to be questioned: experimental philosophy is not in the same position. (10)

Sorell considers this to be "a crucial point" (10). The reason appears to be that it is essential to casting experimental philosophy as being faced with the dilemma described above:

Either experimental philosophy is distinctive or it is not. It seems to proclaim and value distinctiveness. This distinctiveness seems to consist mainly in the application by philosophers of survey methods, including the construction of questionnaires, the identification and recruitment of research subjects, and the processing of results under constraints of achieving statistical significance. Either it uses these methods and is distinctive, in which case its status as philosophy is likely to be questioned, or it is less than distinctive and does not deserve or sustain a manifesto. (10) 
Perhaps Sorell did not mean to be targeting us at this point, but instead aimed only at those experimental philosophers who have written or defended manifestos. We think that Sorell is less than perfectly clear as to his target in this case. But if Sorell's barb was supposed to hit us, then it was misaimed. After all, we explicitly argue against a conception of experimental philosophy on which it would deserve or sustain a manifesto. To emphasize this, we titled the introduction to our volume "An Anti-Manifesto"!

We open our anti-manifesto by noting that "experimental philosophy is often described as a movement, sometimes a revolutionary movement, and [that] the image most often associated with it is the burning armchair" (xvii). Against this, we suggest our more expansive understanding of the philosophical tradition. We write that "we do not think of the contemporary incarnation of experimental philosophy — the new experimental philosophy as we will call it—as either breaking with or contemptuous of traditional philosophy" (xviii-xix). Especially in the introduction to our book, we appealed to the history of philosophy in order to resist a conception of the new experimental philosophy as radically opposed to traditional ways of doing philosophy. Such a radical, destructive conception was encouraged by some early proponents of the new experimental philosophy. Hence, our primary appeal to the history of philosophy is best understood as part of a reply to other experimentalists. In the next section, we will describe our purposes in calling on the history of philosophy in more detail. The current point is that for us, Sorell's dilemma is no dilemma at all, since we reject the idea of a manifesto from the start.

In the final section of his article Sorell restates the dilemma with our more expansive view of experimental philosophy in mind. He argues that such a "lower common denominator threatens to undermine the suggestion of a common ambition" (20). Sorell then notes that while we embrace a "lower common denominator," we nonetheless are faced with his dilemma: 
The problem is that a very inclusive definition of experimental philosophy resulting from their ecumenism either makes urgent the question 'But is it philosophy?' or else it answers that question in the affirmative and experimental philosophy ceases to be different in principle from empirically informed or broadly naturalistic philosophy. (20)

But, again, we happily and explicitly embrace the second horn of this (supposed) dilemma. Our view is that experimental philosophy is not different in principle from empirical philosophy. More carefully, experimental philosophy does not differ in a way that matters for determining whether it is or is not philosophy in the contemporary sense of the term. In fact, we explicitly make that argument in our book!

In rejecting what we take to be a fringe view of philosophy on which it is entirely independent of empirical facts, we appealed to current philosophical practice, noting that "philosophers often make use of empirical findings to advance their philosophical projects." We then quote Sosa $(2007,100)$ noting that the use of empirical results in philosophy is not novel. Sosa suggests that "perhaps the novelty [of experimental philosophy] is rather that experimental philosophers do not so much borrow from scientists as they become scientists." We happily accept Sosa's suggestion, and we remark that this difference would hardly seem to disqualify experimental philosophy as philosophy:

experimental philosophy is thus not too different from what often goes on in the rest of philosophy today. And while actually conducting empirical studies is a bit of a departure from merely using the empirical findings of others (and harkens back to the experimental philosophy of the early modern period), it does not seem like a sufficient departure to push experimental philosophy outside the boundaries of philosophy.... (36)

Our view is that experimental philosophy is a subset of empirical philosophy. We hold that there is an important practical difference between work in experimental philosophy and the rest of empirical philosophy—i.e., that the experimental philosopher is doing empirical work—but we doubt that there is an important theoretical difference. 
Let us emphasize again: we rejected the claim that philosophy is independent of empirical facts by appealing to current philosophical practice, not by appealing to the history of philosophy. This is important insofar as the anti-empirical view of philosophy is closer to the criticism that experimental philosophy is actually psychology than anything else we have discussed. One might imagine a logical positivist such as Ayer claiming that all apparently declarative sentences must be either (empty) logical analysis or (substantive) science or plain nonsense. Formerly, philosophy included all of these. But now, the plain nonsense is to be excised, and the (substantive) science is to be distinguished from philosophy. Hence, philosophy just is (empty) logical analysis. Experimental philosophy is not logical analysis, so it is not philosophy. But it is not plain nonsense either. So, experimental philosophy must be some (substantive) science. Since psychology is similar to experimental philosophy in many respects, and since experimental philosophy is some (substantive) science, experimental philosophy must be psychology (and not philosophy). Now, we do not formulate this argument explicitly in our book, but we do clearly reject the premise that (substantive) science is to be distinguished from philosophy. To echo Williamson (2016, 22): “a few diehard Wittgensteinians may still claim that no outcome of scientific experimentation is of special relevance to philosophy, whose role they confine to dissolving conceptual confusions", but we believe that "philosophy is a theoretical discipline with more constructive ambitions than that."

\section{On Some Uses for History}

We have never appealed to the history of philosophy in order to resist an argument that experimental philosophy is really psychology in disguise, but in our book we did make use of the history of philosophy in other ways besides resisting the destructive conception of experimental 
philosophy. Perhaps Sorell's criticism applies to one of the other ways in which we put the history of philosophy to work. In this section, we discuss three ways in which we might be thought to have called on the history of philosophy.

\subsection{Not a Contradiction in Terms}

The closest that we come to using the history of philosophy in the way that Sorell thinks we do is at the beginning of Chapter 1 of our book, where we discuss the history of philosophy in challenging the assumption that "experimental philosophy" is a contradiction in terms. The most naïve way to frame what we say in the form of an argument is as follows:

[B1] Many philosophers-including canonical philosophers such as Aristotle, Bacon, Descartes, and Leibniz - have at various times used observation and experimentation to answer what they took to be philosophical questions.

[B2] If [B1], then "experimental philosophy" is not a contradiction in terms today.

[B3] "Experimental philosophy" is not a contradiction in terms today.

We expect that Sorell would want to challenge premise [B2], claiming that it begs the question.

Reflecting on our discussion of Descartes in our anti-manifesto, Sorell accuses us of doing essentially this. He writes (7), "The fact that Descartes saw his work in optics as philosophy does not establish that philosophy in his sense is the same as philosophy in the sense of most current practitioners of the subject." In terms of the naïve argument, Sorell might be taken to hold that what the term "philosophy" means_ —or alternatively, what counts as a philosophical question-

has shifted enough in the last two hundred years that whereas "experimental philosophy" was not a contradiction in terms in the early modern period, it is so today. 
We concede that the naïve argument begs the question dialectically against critics of the sort that Sorell imagines. The argument is not intrinsically question-begging, since the conclusion is not assumed as a premise in the argument. But we expect dialectical opponents to reject [B2]. ${ }^{3}$ We also concede that the naïve argument is weak insofar as the truth of [B2] doesn't follow from a simple principle that we accept. For example, one might be tempted to replace [B2] with the following principles:

[Constancy] For all expressions $\mathrm{X}$, if $\mathrm{X}$ was not a contradiction in terms in the past, then $\mathrm{X}$ is not a contradiction in terms today.

[History] If [B1], then "experimental philosophy" was not a contradiction in terms in the past.

Sorell seems to think that we require an assumption such as [Constancy]. However, we agree that [Constancy] is false. The meaning of an expression can change over time in such a way that an expression becomes a contradiction in terms.

In fact, we raise a closely related issue ourselves in Section 2.1.2 (pp. 24-26) of our book. Sorell notes that "to their credit, Sytsma and Livengood actually do devote a great deal of attention to what is reasonably understood by 'philosophical question' in their definition of experimental philosophy" (9). What we do in that section is to discuss how "empirical methods might possibly be used to advance a philosophical investigation" on a number of different accounts of the "sorts of features that might plausibly make an inquiry distinctively philosophical" (21). We survey six types of account, which Sorell briefly summarizes under five headings, running the first two accounts together under the label of "the capacity to produce wonderment relative to a historical context" (9). While the first account ("The Wonderment Account") build's off of Plato's claim that philosophy begins in wonder, the second account

\footnotetext{
${ }^{3}$ See Section 4.2 in Korman (2015) for more on intrinsic and dialectical question-begging.
} 
("The Historical Contingency Account") is not intended to merely relativize the wonderment account. While we introduce this account as a way that one might attempt to remedy the worry that "the wonderment account classifies as distinctively philosophical too many questions that belong to well-defined disciplines, like physics, chemistry, biology, and psychology, which are often far removed from contemporary academic philosophy today" (24), we treat it as a freestanding account.

In this context, we raise the issue that "what counts as genuine philosophical inquiry has changed over time" (25). While the historical contingency account is given as just one possible account of what makes a question distinctively philosophical, we agree with the sentiment that what counts as philosophical inquiry has changed over time. We certainly didn't take ourselves to be denying this fact in our brief discussion of Descartes in the introduction to our text. We continue: "Through a long process of specialization and professionalization, many interesting questions about the world and our place in it have been hived off and assigned to distinct disciplines. As a result, academic philosophy today is a narrower field than it once was, and philosophers do not typically claim primary ownership of many questions that were once distinctively philosophical" (25).

But perhaps our discussion of the historical contingency account did not make sufficiently clear our recognition of the historical contingency of the domain of the philosophical. In laying out these accounts, we did not plunk for one in particular, but simply noted that on each account there is room for experimental philosophy. However, we've made our commitment to some historical contingencies regarding the domain of philosophy abundantly clear elsewhere. Here is what we say in another article (Sytsma and Livengood, 2012) in the context of a statement from Sir Francis Crick asserting that there is a sharp methodological 
divide between philosophy and the sciences. After noting that "with the development of experimental philosophy over the past decade... an increasing number of philosophers are crossing this divide," we briefly discuss the history:

Of course, historically speaking, the divide between philosophy and the sciences has not always been so sharp as Crick suggests. Not only was it once philosophers who were primarily concerned with questions about the nature of matter, for example, but those philosophers made significant progress toward answering them. In fact, the first people to call themselves experimental philosophers - Robert Boyle, Isaac Newton, and some of their contemporaries - were working on problems in what we would now call physics or chemistry. (2)

And on the next page we continue:

Looking across the history of philosophy since the early modern period, what we see is a process of specialization, with the sciences slowly breaking away from the mother discipline of philosophy. And, as this has occurred, philosophy has increasingly become focused on theoretical speculation over empirical investigation. In fact, many philosophers came to embrace methods that have been thought to be independent of empirical investigation, such as conceptual analysis. (3)

We hope that with these remarks in view, Sorell would agree that we have not overlooked the historical contingency of the philosophical.

Given that we agree that [Constancy] is false, how should one understand our use of the history of philosophy in relation to the claim that "experimental philosophy" is not a contradiction in terms today? The answer is that for us [B2] expresses (or attempts to express) in deductive terms what we take to be an inductive inference. The fact that observation and experimentation have been called on by philosophers at many times in history in order to answer questions that they took to be philosophical questions gives us some reason to think that we can do the same today. And if we can do the same today, then "experimental philosophy" is not currently a contradiction in terms. 


\subsection{Can observation and experimentation help?}

Our use of the history of philosophy in Chapter 1 is obviously intended as a gentle introduction aimed to get readers to take seriously the possibility that observation and experimentation are useful in philosophical inquiry. For this reason, we conclude our initial discussion of the history of philosophy with the following observation: "Philosophers can fruitfully employ empirical methods in attempting to answer philosophical questions and solve philosophical problems, and they have frequently done so" (5). This suggests the following weaker appeal to the history of philosophy:

[C1] Many philosophers - including canonical philosophers such as Aristotle, Bacon, Descartes, and Leibniz - have found observation and experimentation to be useful for answering what they took to be philosophical questions.

[C2] If [C1], then it is worth considering whether observation and experimentation might be useful for answering philosophical questions today.

[C3] It is worth considering whether observation and experimentation might be useful for answering philosophical questions today.

On this framing, our appeal to the history of philosophy is suggestive only. The real work is done in Chapters 2 and 3, where we describe ways in which experimentation might help us answer philosophical questions and ways in which experimentalists have contributed to contemporary philosophical inquiry. Here is how we express this at the start of Chapter 2 :

Some of our readers may be inclined to think that philosophy is, by its very nature, not the sort of thing that could be advanced by empirical inquiry, and hence that there could never be any reason for a philosopher qua philosopher to engage in empirical work. By sketching how experimental philosophy could contribute to philosophy on each of our six accounts, we hope to convince neutral readers that there is plenty of room for empirical work in contemporary philosophy. (23)

Ultimately, we think it is more helpful to turn Sorell's problem on its head. The right question to ask is not, "Is experimental philosophy really philosophy?" The right question to ask is, "Can 
observation and experimentation help us to answer contemporary philosophical questions?" We think that the history of philosophy—when viewed in a certain way—can help to motivate the question. But the question is not definitively answered one way or the other by appeal to the history of philosophy. To be clear, we think that the answer to the question is "yes": observation and experimentation can help us to answer some of our philosophical questions. But that does not in any way imply that empirical research is the only way to answer philosophical questions or that it will help us to answer every philosophical question.

Notice now one further way in which our arguments work. Suppose one accepts that it is at least worth considering whether observation and experimentation might be useful for answering philosophical questions today. And suppose one is then convinced by our discussion of philosophical questions and contributions of experimental philosophers in Chapters 2 and 3 of our book. Then it should be obvious that "experimental philosophy" is not a contradiction in terms today.

\subsection{The "Tradition" as Aberration}

In closing out this section, we want to consider a final way in which we appeal to the history of philosophy. We noted in Section 1 that in the introduction to our book we appealed to the history of philosophy in resisting the conception of the new experimental philosophy as radically opposed to traditional ways of doing philosophy. The new experimental philosophy is often described as a revolt against "traditional" philosophy. One imagines a mob of experimentalists standing on the barricades, screaming: "Burn the armchairs!" Our goal in calling on the history of philosophy was to raise doubts about this conception of experimental philosophy by raising doubts about the conception of the philosophical traditional that it is revolting against. Our view 
is that observation and experimentation are also a part of the philosophical tradition. And we called on the example of Descartes to illustrate the point.

At the same time, we recognize that philosophy has changed over time. As we note above, we acknowledge that over time "philosophy has increasingly become focused on theoretical speculation over empirical investigation" (Sytsma and Livengood, 2012, 3). Consequently, some have come to think of traditional philosophy as divorced from empirical investigation - as an "armchair" discipline. Our goal was simply to indicate that there is more to the tradition than this, and that relative to a more expansive view of the tradition, experimental philosophy is not revolutionary.

Therefore, we prefer to think of the new experimental philosophy as counterrevolutionary. On our view, the real revolution against traditional philosophy advanced a conception of philosophy as an armchair discipline. This revolution - perhaps due to the logical positivists, perhaps due to the linguistic turn, or perhaps due to something else- - threw away empirical methods as irrelevant to philosophy, though as we note in our book, "the use of empirical methods in philosophy did not completely disappear" (5). On our view, experimental philosophers are aiming to restore those methods to their proper place alongside, but not excluding, other methods of philosophy. Hence, the guiding metaphor of our volume was that the new experimental philosophy returns a tool to the philosophical toolbox.

Put another way, we hope that history will come to see the current conception of the philosophical tradition as an aberration. In this respect, Sorell is right to say that contemporary philosophy prior to the rise of the new experimental philosophy is different from traditional philosophy. That fact now does very different work, however. Pre-experimental contemporary philosophy diverges from the longer tradition in often conceiving of philosophy as an armchair 
discipline. But we reject this conception. As we argued earlier in this paper, we think philosophy is better demarcated in terms of the questions asked than the methods employed. Many philosophical questions can (at least in part) be addressed using empirical methods, and experimental philosophers seek to do so. Thus, we urge contemporary philosophers to be more like the early moderns and (when appropriate) to call on empirical methods to help answer our shared, distinctively philosophical, questions. 


\section{References}

Ayer, A.J. (1952). Language, Truth and Logic. New York: Dover.

Buckwalter, W. and J. Sytsma (2016). "Introduction.” In J. Sytsma and W. Buckwalter (eds.), A Companion to Experimental Philosophy. Oxford: Blackwell.

Korman, D. (2015). Objects: Nothing out of the ordinary. Oxford University Press.

Sorell, T. (2018). "Experimental Philosophy and the History of Philosophy." British Journal for the History of Philosophy, 26(5): 829-849.

Sosa, E. (2007). "Experimental Philosophy and Philosophical Intuition.” Philosophical Studies, 132 (1): 99-107.

Sytsma, J. (2010). "The Proper Province of Philosophy: Conceptual Analysis and Empirical Investigation." Review of Philosophy and Psychology, 1(3): 427-445.

Sytsma, J. (2016). "Rethinking the Scope of Experimental Philosophy." Metascience, 25(2): 301304.

Sytsma, J. (2017). “Two Origin Stories for Experimental Philosophy.” teorema, 36(3): 23-43.

Sytsma, J. and J. Livengood (2012). "Experimental Philosophy and Philosophical Disputes." Essays in Philosophy, 13(1): 145-160.

Sytsma, J. and J. Livengood (2016). The Theory and Practice of Experimental Philosophy. Broadview.

Sytsma, J. and E. Machery (2013). "Experimental Philosophy," in B. Kaldis (ed.), Encyclopedia of Philosophy and the Social Sciences, pp. 318-320. Thousand Oaks, CA: SAGE.

Williamson, T. (2016). "Philosophical Criticisms of Experimental Philosophy," in J. Sytsma and W. Buckwalter (eds.), A Companion to Experimental Philosophy. Malden, MA: Wiley Blackwell. 